\title{
O PLURALISMO JURÍDICO COMUNITÁRIO-PARTICIPATIVO RESSONANTE O DIREITO DE FAMÍLIA
}

\author{
Silvia Ozelame Rigo Moschetta ${ }^{1}$
}

Resumo: $\mathrm{O}$ artigo aborda o pluralismo jurídico comunitário-participativo ressonante no Direito de Família. É possível reconhecer os fundamentos da teoria do pluralismo jurídico comunitário-participativo no âmbito do Direito de Família? Objetiva-se analisar os fundamentos da teoria do pluralismo jurídico comunitário-participativo no âmbito do Direito de Família; especificamente, compreender os aportes teóricos do pluralismo jurídico comunitário-participativo; o Direito de Família na Pós-Modernidade; três fundamentos da teoria do pluralismo jurídico comunitário-participativo. $\mathrm{O}$ método de abordagem é o dedutivo e o método de procedimento o monográfico. Ao fim, apresentam-se três fundamentos da teoria do pluralismo jurídico comunitário-participativo ambientados ao Direito de Família.

Palavras-chave: Pluralismo Jurídico Comunitário-Participativo; Direito de Família; Sujeito Coletivo; Afetividade; Mediação Familiar.

\section{THE COMMUNITY-PARTICIPATORY LEGAL PLURALISM RESONANT IN THE FAMILY LAW}

\begin{abstract}
The article addresses the resonant community-participatory legal pluralism in Family Law. Is it possible to recognize the foundations of the theory community-participatory legal pluralism in the context of Family Law? The objective is to analyze the foundations of the theory of community-participatory legal pluralism in the context of Family Law; specifically, to understand the theoretical contributions community-participatory legal pluralism; Family Law in Post-Modernity; three grounds of the theory communityparticipatory legal pluralism. The method of approach is the deductive and the method of the monographic procedure. Finally, three grounds of the theory community-participatory legal pluralism in the context of Family Law.
\end{abstract}

Keywords: Community-Participatory Legal Pluralism; Family Law; Collective Subject; Affectivity; Family Mediation

\footnotetext{
${ }^{1}$ Doutora em Direito pela Universidade Federal de Santa Catarina - UFSC; Docente na Universidade Comunitária da Região de Chapecó - UNOCHAPECÓ.
}

Revista de Direito de Família e Sucessão | e-ISSN: 2526-0227 | Porto Alegre | v. 4 | n. 2 | p. 18 - 39 | Jul/Dez. 2018 


\section{INTRODUÇÃO}

A Pós-Modernidade, marcada pelas conquistas e desafios experienciados pela Modernidade, cuja contribuição não se deixa de ponderar, acaba proporcionando outro olhar para questões atuais e futuras, cuja pauta se estabelece pela atuação de um novo sujeito.

O pluralismo jurídico comunitário-participativo encampa um modelo aberto que tem na figura dos sujeitos sociais a regulação das instituições-chave da sociedade, privilegiando o Direito como um fenômeno resultante de relações sociais e valorações desejadas para se instaurar outra legalidade, a partir da multiplicidade de fontes normativas não obrigatoriamente estatais. Vale dizer que, nesta pesquisa, esses sujeitos sociais são as famílias, e as necessidades humanas fundadas na legalidade se estreitam na afetividade entre os pares, nas questões envolvendo vínculos afetivos que possuem o condão de fundamentar o reconhecimento jurídico. Isso aponta para novos rumos de exercício e tutela de direitos, sobretudo no ambiente dos conflitos familiares em que a intervenção emerge a partir da mediação familiar.

A Família não é a única instituição protegida pelo Estado, mas recebe um tratamento especial, pois é a partir dela que se constituem os grupos que comporão o tecido social. Sob a égide dessa imbricação é que se percebem as mudanças por que ela passou: partindo de uma concepção rígida fulcrada em dogmas religiosos petríficos, viu-se enclausurada em suas próprias amarras, comprometendo o animus dos envolvidos, que, em algumas uniões, careciam de reconhecimento jurídico. Transpor a dimensão do Direito de Família em sua definição significa romper com o legado deixado e buscar novas inspirações que se corporifiquem em novos direitos e deveres, tanto referentes ao casal como à descendência, situações desafiadoras que serão abordadas nesta pesquisa.

O presente artigo tratará, em sua primeira parte, acerca dos aportes da teoria do pluralismo jurídico comunitário-participativo, ressaltando sua ambientação diante da necessidade de múltiplas práticas jurídicas condizentes com as necessidades materiais e imateriais dos sujeitos. Em seguida, será abordada a contextualização jurídica das famílias na Pós-Modernidade, seus anseios e conflitos. Por derradeiro, analisar-se-á se os fundamentos da teoria do pluralismo jurídico comunitário participativo são ressonantes no Direito de Família, a saber: como sujeito coletivo, necessidades humanas fundamentais e prática interventivoparticipativa nos conflitos familiares.

A pesquisa apresenta-se com a seguinte problemática: é possível reconhecer os

Revista de Direito de Família e Sucessão | e-ISSN: 2526-0227 | Porto Alegre | v. 4 | n. 2 | p. 18 - 39 | Jul/Dez. 2018 
fundamentos da teoria do pluralismo jurídico comunitário-participativo no âmbito do Direito de Família?

O objetivo principal recai sobre a análise dos fundamentos da teoria do pluralismo jurídico comunitário-participativo no âmbito do Direito de Família. Como objetivos específicos, estes: compreender os aportes teóricos do pluralismo jurídico comunitário participativo; analisar o Direito de Família na Pós-Modernidade; verificar três fundamentos da teoria do pluralismo jurídico comunitário-participativo.

Para a elaboração desta pesquisa, será empregada a pesquisa bibliográfica como procedimento técnico, com exame da doutrina e legislação correlata ao tema. Ainda, valer-seá de análise documental referente à matéria, sendo que a coleta de dados se dará por meio do estudo de documentos afins. Em complementaridade, o método de abordagem será dedutivo e a técnica de análise de dados será qualitativa, com investigação de conteúdo.

Munida de origens diferentes e caracterizações múltiplas, utilizar-se-á para a pesquisa o principal núcleo da teoria do pluralismo jurídico: a negação de que o Estado seja a única e exclusiva fonte de todo o Direito; e essa averiguação será feita quando se analisar o Direito de Família, especialmente se os sujeitos que constituem suas famílias e encaminham os conflitos advindos desse ambiente familiar podem procurar outros espaços e condições paraestatais como alternativa para ressignificarem suas desavenças. Esse agir que se traduz em identificar as necessidades da união e suas responsabilidades, mesmo que amparadas pelos direitos dela decorrentes, pode revelar uma prática emancipatória e participativa, embalada pelos fundamentos do pluralismo jurídico, forte na mediação.

\section{APORTES DO PLURALISMO JURÍDICO COMUNITÁRIO-PARTICIPATIVO}

Ao adentrar na teoria do pluralismo jurídico, cabe esclarecer que os limites da pesquisa se circunscrevem a observar o pluralismo jurídico como resposta ao normativismo estatal positivista e sua concepção de práticas participativas. Por isso expõe-se a definição dada por Wolkmer (2006, p. 637, grifos do autor), que ambienta aquela surgida em 1939, no ambiente da economia europeia:

Pluralismo jurídico é a conjunção das expressões de origem latina plural/pluralis (multiplicidade de elementos ou formas de ação; contraponto ao uno, ao centralismo) com juridicus (relacionado ao Direito, ao legal e ao jurídico). Ainda que as investigações contemporâneas de seu conteúdo tenham sido registrados pela escola holandesa do jurista Van Vollenhoven, que examinou o Direito costumeiro dos grupos autóctones na Indonésia, foi J. S. Furnivall quem, em 1939, utilizou a

Revista de Direito de Família e Sucessão | e-ISSN: 2526-0227 | Porto Alegre | v. 4 | n. 2 | p. 18 - 39 | Jul/Dez. 2018 
expressão pela primeira vez, ao descrever, de forma específica, o pluralismo na economia de sociedades submetidas ao expansionismo europeu.

Por ser uma manifestação universal, o pluralismo jurídico não surgiu com a Modernidade ou Pós-Modernidade, aliás, as primeiras manifestações se apresentaram na civilização romana, pois Roma vivenciava experiências de grande diversidade jurídica, como ambientar normas oficiais - as de direito público restrita aos sacerdotes, nos sacra (coisas sagradas) e aos magistrados (PILATI, 2011, p. 81) - com normas de direito privado que se orientavam, por exemplo, pelas contribuições deixadas por Justiniano, codificadas no Digesto. Além das normas públicas e privadas, tinha-se, ainda, as normas vigentes dos povos dominados pelos romanos, vale dizer, normas não oficiais, sendo que todas coexistiam mesmo que de distintos jaezes (WOLKMER, 2006, p. 638; WOLKMER, 1997, p. 169).

A partir da manifestação do pluralismo jurídico, foi possível a introdução de uma nova epistemologia no cenário ocidental. Outras teorias sociológicas para se revolver a "crise do Direito" foram apresentadas no decorrer dos tempos ${ }^{2}$, mas o olhar, neste artigo, se volta à teoria do pluralismo jurídico comunitário-participativo, de Antônio Carlos Wolkmer.

A modernidade jurídica alicerçada na via de que o Estado emanava seu poder pela legalidade viu-se comprometida, e sua eficácia, ameaçada, posto que presentes conflitos sociais e novos direitos não abrangidos pela mão estatal, o que permitiu espaço para se repensar novos padrões de referência e legitimação (WOLKMER, 2012, p. 235).

A prática do pluralismo jurídico inclui a proposta de revisão do dogmatismo jurídico e a investigação do fenômeno jurídico tendo como pressuposto a emancipação (RUSSO, 1996, p. 349). O pluralismo jurídico representa a "multiplicidade de práticas jurídicas existentes num espaço sociopolítico, interagidas por conflitos ou consensos, podendo ser ou não oficiais e tendo sua razão de ser nas necessidades existenciais, materiais e culturais" (WOLKMER, 1997, p. 195; WOLKMER, 2006, p. 639).

Essa proposta de um "novo" pluralismo jurídico, designado como comunitárioparticipativo, encampa um modelo aberto que tem na figura dos sujeitos sociais a regulação das instituições-chave da sociedade, privilegiando o Direito como um fenômeno resultante de relações sociais e valorações desejadas para se instaurar uma outra legalidade a partir da multiplicidade de fontes normativas não obrigatoriamente estatais, uma legalidade embasada nas justas "exigências fundamentais de atores sociais [...] e encarar a instituição da sociedade como uma estrutura descentralizada, pluralista e participativa" (WOLKMER, 1997, p. 69).

\footnotetext{
${ }^{2}$ Eugen Ehrilch e Georges Gurvitch, sociólogos do Direito, também contribuíram para a construção teórica de um autêntico e original pluralismo jurídico (WOLKMER, 1997, p. 177).
} 
Destaca-se a dimensão do pluralismo trazida por Wolkmer (2013, p. 21):

[...] o pluralismo engloba fenômenos espaciais e temporais com múltiplos campos de produção e aplicação, os quais compreendem, além dos aportes filosóficos, sociológicos, políticos ou culturais, uma formulação teórica e prática de pluralidade no direito. Ora, o pluralismo no direito tende a demonstrar que o poder estatal não é a fonte única e exclusiva de todo o direito, abrindo escopo para uma produção e aplicação normativa centrada na força e na legitimidade de um complexo e difuso sistema de poderes, emanados dialeticamente da sociedade, de seus diversos grupos sociais, coletividades ou corpos intermediários.

A possibilidade de produzir as próprias disposições normativas também ocorre em espaços ou núcleos que não possuem uma instância social autônoma e complexa: em pequenos grupos que possuem condições estratégicas de produção direta, de movimentação de bens e serviços e seus processos decisórios; e suas deliberações implementam ações que repercutirão no âmbito da família, vizinhança, igreja, comitês de bairros, por exemplo (WOLKMER, 1997, p. 161-162).

Isso importa trazer para o cenário das preocupações jurídicas novos sujeitos, novos valores e uma nova legalidade, todos fundamentados na ambiência do paradigma que se denominou Pós-Modernidade, para assim se apresentar uma nova epistemologia que reconheça e encaminhe os conflitos advindos desse contexto contemporâneo e complexo. Esse "encaminhamento" dos conflitos dar-se-ia utilizando mecanismos não oficiais, paralegais, para viabilizar aos sujeitos o que eles desejam e necessitam, partindo de uma esfera particular, interna para se corporificar numa decisão assumida e responsável. No decorrer da pesquisa, procurar-se-á averiguar se essa realidade encontra ressonância no Direito de Família.

Para sistematizar e articular esse projeto cultural pluralista e interdisciplinar que permite aduzir um "novo" direito, serão apresentados, a seguir, os fundamentos do pluralismo jurídico como um novo paradigma: os fundamentos de efetividade material que engloba os novos sujeitos coletivos de juridicidade e o sistema das necessidades humanas fundamentais; os fundamentos de efetividade formal que se referem à reordenação política do espaço público (democracia, descentralização e participação), ética concreta da alteridade e racionalidade como necessidade e emancipação.

Os novos sujeitos coletivos de juridicidade integram os fundamentos de efetividade material que importam reconhecer uma sustentação paradigmática do projeto pluralista, em que o sujeito coletivo de direito "é um sujeito vivo, atuante e livre, que se autodetermina, participa e modifica a mundialidade do processo histórico-social”, cujo surgimento se dá nas “identificações valorativas e experiências vividas, buscando a satisfação das necessidades e 
demandas por direitos" (WOLKMER, 1997, p. 211, 215).

Wolkmer (1997, p. 214) direciona para os novos sujeitos históricos, afirmando:

[...] são situados como identidades coletivas conscientes, mais ou menos autônomas, advindos de diversos estratos sociais, com capacidade de auto-organização e autodeterminação, interligadas por formas de vida com interesses e valores comuns, compartilhando conflitos e lutas cotidianas que expressem privações e necessidades por direitos, legitimando-se como força transformadora do poder e instituidora de uma sociedade democrática, descentralizada, participativa e igualitária.

Essa perspectiva de um novo sujeito coletivo contrasta com a ideia de sujeito individual inaugurada pela Modernidade, que, inclusive, supera o racionalismo medieval, pois o homem medieval é chamado a querer, "um homem que se projeta para fora em atitude de humildade" e passa a ser chamado, pela razão moderna, como "um homem que encontra em si mesmo toda justificação e que projeta para fora unicamente sua pretensão de dominar o mundo, de colocar-se como soberano do mundo" (GROSSI, 2007, p. 1).

O exemplo que se apresenta como sujeito coletivo de direito é o da família, implicando reconhecê-la como um direito fundamental de todos, pois a interpretação constitucional assim a considerou quando dispôs (art. 200) ${ }^{3}$, referenciando a Lei n. 8.080 de 1990 (art. $2^{\circ}, \S 2^{\circ}$ ), por conta dos "termos da lei”, que o dever do Estado de prover as condições indispensáveis ao exercício da saúde não exclui o dever da família. Mesma constatação se estende quando se trata da educação, porquanto é dever do Estado e da família, o que equivale a dizer que a responsabilidade é a mesma na consecução de direitos e deveres, equiparando-as, portanto.

Muito embora o sujeito de direito agregue a titularidade de direitos e deveres na esfera do Direito, não se pode comparar sujeito de direito com pessoa física ou jurídica. Pois, toda “[...] pessoa física ou jurídica é um sujeito jurídico. A recíproca, porém, não é verdadeira.” (FERRAZ JÚNIOR, 2008, p. 127). No entanto, quer-se ir além do aporte doutrinário para se entoar um novo hino, que proclame a família como sujeito coletivo de direito, caracterizada como coletividade privada extrapatrimonial, marcada pela participação.

Assim, tem-se um homem que queria conhecer, outro que desejava ser soberano do mundo, para, sobretudo, apresentarem-se novos sujeitos coletivos com incidência jurídica, que possuem comportamentos orientados por uma função coletiva, comprometidos consigo mas com os outros também, numa relação de alteridade, cujos propósitos são a satisfação das necessidades fundamentais e a postulação de seus direitos.

Na ambiência dos novos sujeitos coletivos de juridicidade é que surgem as necessidade humanas fundamentais, que são o segundo fundamento de efetividade material que se expõe.

\footnotetext{
${ }^{3}$ Art. 200. “Ao sistema único de saúde compete, além de outras atribuições, nos termos da lei: [...]” (BRASIL, 1988).
} 
Elas não se reduzem exclusivamente às necessidades materiais, mas se estendem às existenciais e culturais, sendo experienciadas por sujeitos, que, segundo Wolkmer (1997, p. 144),

[...] são atingidos na sua dignidade pelo efeito perverso e injusto das condições impostas pelo alijamento do processo de participação e desenvolvimento social, e pela repressão e sufocamento da satisfação das mínimas necessidades. Na singularidade da crise que atravessa o imaginário instituído e que degenera as relações da vida cotidiana, a resposta para transcender a exclusão e as privações provêm da força contingente de novos agentes coletivos que, por vontade própria e pela consciência de seus reais interesses, são capazes de criar e instituir novos direitos.

O que entoa os novos direitos são as necessidades humanas fundamentais, relacionadas tanto à "falta ou privação de objetos determinados (bens materiais inerentes à produção humana em sociedade) quanto à ausência subjetiva de algo imaterial relacionado ao desejo, ações, normas, posturas, modo e formas de vida, valores” (WOLKMER, 1997, p. 218).

Ainda, Wolkmer (1997, p. 222, grifos do autor) afirma que

[...] o conjunto das necessidades humanas fundamentais, quer como núcleo gerador de novos sujeitos coletivos, quer como força motivadora e condição de possibilidade de produção jurídica, tem sua gênese num amplo espectro de causalidades qualitativas e quantitativas, objetivas e subjetivas, materiais e imateriais, reais e ilusórias [...]. Em suma, é nas condições de nosso processo histórico-social periférico, marcado por formas de vida inseridas na eclosão de conflitos, contradições e insatisfação de necessidades materiais, que se interpõe a reivindicação de "vontades coletivas", em defesa dos direitos adquiridos e na afirmação ininterrupta de "novos" direitos a cada momento.

Como o sistema de necessidades está entrelaçado com os novos sujeitos coletivos, e por elas serem inesgotáveis e ilimitadas no tempo e no espaço, estando sempre em constante redefinição e criação (WOLKMER, 2007, p. 102), urge destacar, no âmbito da pesquisa, as necessidades de composição familiar plural, que se desvinculam da família tradicional, burguesa, hierarquizada, matrimonial, permitindo que outras tipologias familiares sejam albergadas pelo manto desse novo paradigma pluralista.

Além dos fundamentos de efetividade material descritos, torna-se essencial incluir as estratégias de efetividade formal que estão vinculadas à reordenação do espaço público, à ética da alteridade e à racionalidade emancipatória.

Inicia-se pela reordenação do espaço público que importa para Wolkmer (1997, p. 226):

[...] a construção de uma sociedade democrática alicerçadas nas necessidades das identidades coletivas locais não só depende da participação integral de uma cidadania consciente e atuante, como ainda tem sua condição prévia nos marcos de descentralização político-administrativa e na redistribuição racional de recursos, competências e funções.

Essa reorganização do espaço público se coaduna com a utilização de mecanismos que podem operacionalizar a prática de democracia participativa; por isso, afirmar que uma Teoria 
Pós-Moderna do Direito atingiu seu núcleo duro significa destacar a CRFB/88, "quando se insculpiu no art. $1^{\circ}$, parágrafo único que: Todo o poder emana do povo, que o exerce por meio de representantes eleitos ou diretamente, nos termos da Constituição" (PILATI, 2015, p. 24, grifo do autor). Esse mandamento permite, além de democracia direta e sistema representativo, a participação direta em casos de bens constitucionais, como saúde, ambiente, educação família, patrimônio cultural, que significam bens dos brasileiros e não da República Federativa do Brasil.

A questão de transição paradigmática não avançará enquanto não se definir o "marco jurídico de absorção dos novos conflitos: construir a doutrina de concretização da ordem constitucional de 1988" (LEHMANN, 2014, não paginado). Sendo assim, a prática participativa da comunidade na administração da Justiça envolve a democratização do acesso à Justiça, que tem na metodologia da mediação um exemplo (WOLKMER, 1997, p. 230), permitindo inserir a mediação familiar como uma prática participativa em que o casal procura encaminhamento de seu conflito familiar para que, a partir de suas próprias compreensões e decisões, se construa a intervenção necessária.

Assim, para Wolkmer (1997, p. 233),

[...] o que importa ter presente na reordenação política do espaço público, com o consequente processo de democracia descentralizada e participativa, é descortinar uma sociedade pluralista marcada pela convivência dos conflitos e das diferenças, propiciando uma outra legitimidade embasada nas necessidades fundamentais de sujeitos coletivos insurgentes, que, com suas práticas, relações e reivindicações cotidianas, passam a ser encarados como fontes de produção jurídica não-estatais.

A ética da alteridade não deixa de ser a formulação de uma nova ordem de valores éticos, que se expressa não somente nos valores racionais como "vida, liberdade, bem-comum e justiça", mas por ser "parte de uma pluralidade de formas de vida, traduz a singularidade de certos valores específicos [...], representados basicamente pela emancipação, autonomia individual e coletiva, solidariedade, justiça e a satisfação das necessidades humanas" (WOLKMER, 1997, p. 233, 241).

A ética da alteridade é uma "ética antropológica da solidariedade" que emerge das necessidades humanas daqueles que se encontram marginalizados, e possui como intuito gerar uma "prática pedagógica libertadora" que seja capaz de emancipar os "sujeitos históricos" que estão oprimidos, injustiçados e excluídos (WOLKMER, 1997, p. 241).

A questão de cruzamento, concorrência e convivência de valores éticos racionais universalizantes com valores éticos particulares se delineia de forma complexa, o que permite aceitar que, "em determinadas condições estruturais e conjunturais, é possível constituir 
categorias éticas em decorrência de situações singulares e em consonância com experiências concretas vivenciadas" (WOLKMER, 1997, p. 243).

Para Wolkmer (1997, p. 244), deve-se

[...] reconhecer na contextualização periférica da cultura capitalista latino-americana e brasileira, as possibilidades de uma nova ética de teor pedagógico e libertário, gerada no bojo de relações conflituosas e de práticas cotidianas configuradas, quer por sujeitos coletivos, indistintamente, quer especificamente pelos novos movimentos sociais.

O terceiro e último fundamento de efetividade formal do novo paradigma jurídico dirige-se para a racionalidade emancipatória, a qual objetiva descrever os processos racionais de conhecimento que, além de refletirem interesses, carências e necessidades vitais, estejam comprometidos com a emancipação e autonomia da essência humana (WOLKMER, 1997, p. 244).

Preconiza Wolkmer (1997, p. 253, grifos do autor) que

[...] o pluralismo como paradigma de uma nova cultura político-jurídica tem a necessidade de se sustentar em mecanismos instrumentais que possam viabilizar sua "estrutura formal" direcionada à "ação prática coletiva" (desenvolvimento de uma cidadania coletiva), a "ação prática individual” (percepção e favorecimento de valores éticos da alteridade) e, por fim, a ação teórica a nível do saber e do conhecimento, objetivando processos emancipatórios. Dentre todos os mecanismos instrumentais, há de se optar por aquele mais capaz de romper com os obstáculos do velho paradigma e lançar as bases para um novo homem, uma nova sociedade, um novo comportamento e um novo conhecimento.

Uma racionalidade que prime pela emancipação não tem outro fundamento senão o de promover um novo contexto jurisdicional e vencer a utilização do método de racionalidade do Direito eminentemente formal, o qual enaltece um positivismo novecentista, comprometendo a eficácia perante o corpo social.

Não se resolvem os problemas atuais com o arcabouço jurídico de outrora, ou seja, é necessário "abduzir o pensamento jurídico, e levá-lo à perspectiva da Pós-Modernidade" (PILATI, 2013, p. xii), a partir de uma teoria correspondente aos desafios atuais, "com novas formas de mediar os conflitos”, uma readequação preservando as conquistas modernas: “[...] liberdade, propriedade, Estado, segurança jurídica, democracia, Constituição. Tão somente o restabelecimento da dignidade do Direito como instrumento efetivo e eficaz de mediação do novo a partir do conflito mesmo." (PILATI, 2015, p. 15).

Para Russo (1996, p. 318), a Pós-Modernidade permite uma desconstrução, não uma demolição, e cabe ao jurista deixar a porta aberta para que se apresentem racionalidades alternativas, as quais proporcionam horizontes de sentido, mesmo utópicos. Assim, diante da crise institucional (Estado, democracia representativa), crise de valores (fundamentos, 
princípios, ética) e crise de justiça, "urge repensar e propor perspectivas críticas e emancipadoras para o direito contemporâneo" (WOLKMER, 2007, p. 96).

Diante dos fundamentos jurídicos apresentados, procurou-se analisar os reclamos da Pós-Modernidade para, assim, concebê-la com uma nova roupagem jurídica, marcada por um espectro teórico de um novo "agir jurídico", ambientado na consciência de "um novo sujeito de direito": o sujeito coletivo de juridicidade que busca suas necessidades humanas e aguarda mecanismos instrumentais aptos para conduzir consensos e dissensos advindos das relações sociais, e, em especial, das relações familiares, para, assim, atender com eficácia, eficiência e efetividade os rumos, no caso, do Direito de Família.

\section{O DIREITO DE FAMÍLIA E OS FUNDAMENTOS DA TEORIA DO PLURALISMO JURÍDICO COMUNITÁRIO-PARTICIPATIVO}

Para vencer ou mesmo abrandar a rigidez das normas, o direito civil constitucional parte do princípio do dogmatismo atrelado a sua crítica, com renovação de categorias de direito privado e, no caso desta pesquisa, atenção para a categoria da família; por isso que a constitucionalização do Direito de Família maximizou a existencialidade em prol de sujeitos livres, desejantes e autônomos.

A afirmação de democracia representativa no "vazio" possui um tom de permissividade política, cultural, econômica, religiosa e jurídica, o que envereda para uma sociedade plural que acolhe, por exemplo, entidades familiares que não estão previstas no formato rígido da lei. Para Soares (2008, p. 18), a pauta é de um Direito de Família pós-moderno:

[...] guiado por um novo modelo de racionalidade, pois não se admite a neutralidade axiológica e o distanciamento social que caracterizaram o exercício da razão moderna. Prova disso é a flagrante extensão do próprio conceito de racionalidade, desembocando na ideia de uma razão comunicativa, que abarca não só a relação cognitiva do sujeito com as coisas (esfera do ser), como também contempla os valores (esfera do dever ser), sentimentos e emoções (esfera das vivências pessoais).

A CRFB/88 incorporou em seu texto alguns institutos fundamentais; entre eles, a entidade familiar brasileira. Até a promulgação da Constituição, o cenário do Direito de Família estava, de certa forma, fragilizado, já que se dispunha de um Código Civil cujas regras atinentes à família haviam sido praticamente revogadas, fazendo surgir legislações infraconstitucionais para suprir os textos revogados e contemplar as modificações sociais.

Percebe-se, nesse contexto, um divisor de águas entre a família codificada na década de 1920 e a família constitucionalizada na de 1980: aquela, caracterizada como 
matrimonial, patriarcal, heterossexual e hierárquica; esta, caracterizada pela informalidade (união estável), monoparentalidade (comunidade formada por qualquer dos pais e seus descendentes), respeito à diversidade sexual e igualdade conjugal. Observa-se a despatrimonialização da família, no sentido de louvar a existencialidade, tendo essa instituição como ninho de afeto e realização, primando-se pela promoção da dignidade de seus membros.

A CRFB/88 traçou uma nova ratio para a concepção individualista pregada pelo Código Civil; estabeleceu fundamentos para tratar, por exemplo, das relações contratuais, da propriedade e da família, marcos significativos da vida privada que, agora, são observados por meio da cidadania, dignidade e valores sociais. Toda essa inversão axiológica trazida pelo texto constitucional também refletiu no reconhecimento legal da família como base da sociedade, assegurada a especial proteção do Estado.

Além de trazer a pessoa humana para o umbigo das preocupações jurídicas, a Carta de Outubro também rompeu com o modelo estigmatizado de família, condicionado ao matrimônio, e recepcionou, dentro de uma concepção plural, outras formações familiares existentes que estavam marginalizadas de seu reconhecimento jurídico (FACHIN, 2000, p. 136).

A família representa uma interação de indivíduos na qual cada um exerce determinados papéis e funções socialmente relevantes, sem que, necessariamente, estejam ligados biologicamente (FACHIN, 2006, p. 315; PEREIRA, 2003, p. 13). Diante dessa concepção, observa-se que a função da família não é mais patrimonialista - marco do século passado, quando a propriedade gerava o anseio de constituição -, mas, sim, a realização pessoal de cada um, almejando a felicidade, que sustenta as entidades familiares coevas. A pessoa, em vez da propriedade, deverá estar no centro do rancho familiar.

A família se traduz como uma agremiação destinatária de projetos e de discursos, especialmente da "alocução normativa, junção que encarna o elo entre o direito, a família e a sociedade", para assim se compreender "o mundo da família e a família no mundo" (FACHIN, 2003, p. 3). Assim, a família, como sujeito de direito, transborda a subjetividade e se lança para um espaço coletivo extrapatrimonial, cuja formatação lhe garante uma função social. Hodiernamente, observa-se que a família resgata resquícios de convivência intergeracional: pais vivem com os filhos, bem como avós com netos - todos no mesmo espaço territorial. Por outro lado, vence-se a clausura da diferença de gêneros e congrega-se 
um liame mais íntimo e sincero: o afeto entre aqueles ou aquelas que decidem conviver.

Essa convivência em um paradigma que conecta a experiência da Modernidade com a Pós-Modernidade reclama uma família social, econômica, política e responsável pela sua prole. Para Fachin (2006, p. 315),

[...] como sua origem, a crise da família também é social. E, enquanto social,
necessariamente econômica. Isso porque com a decadência da propriedade burguesa a
herança, mola propulsora da obediência familiar, passa a ter menos valor; com a
possibilidade de auferir seu próprio sustento, a autoridade sobre os filhos já não é
exercida do mesmo modo. Assim, como o advento moderno da estrutura socioeconômica
capitalista, há um desequilíbrio entre o que a família oferece e o que ela cobra de seus
membros.

A entidade familiar rompe com o paradigma moderno e passa de fim em si mesma, em que não se questionam as razões de ser, para meio de valorização e potencialidade de seus integrantes, maximizada a dignidade de cada ser. Ora, sem família, não há sociedade, além de ela ser um "locus privilegiado para o desenvolvimento pleno da personalidade de seus membros" (GAMA, 2007, p. 119-127).

Assim, a releitura contemporânea que se faz de "família" é a de que ela deriva do afeto e não somente da ordem jurídica, pois, como fato cultural, está antes e acima do Direito e nas entrelinhas do fato jurídico, cuja situação jurídica é subjetiva, individual ou coletiva; e observá-la somente com as lentes do ordenamento é enxergá-la sem vê-la em sua totalidade (FACHIN, 2006, p. 314).

A constitucionalização do Direito de Família implica o reconhecimento da afetividade como valor essencial da família. A democratização do espaço familiar não é outra garantia posta senão a garantia do casal em se apropriar de seus conflitos privados e públicos; de, a partir da decisão orientada, esse espaço familiar se traduzir em um ambiente de crescimento, de tomada de consciência de direitos e obrigações em prol de uma vida justa.

A situação que se observa no Brasil não é diferente das experiências europeias, a necessidade é a mesma: Grossi (2004, p. 13-14) enfatiza a exigência de um repensamento epistemológico que requer uma ruptura entre o direito vivido hodiernamente e o experienciado na Modernidade da Europa continental, em que as chaves das portas foram entregues aos detentores do poder, elevados à condição de representantes da vontade geral e do direito para a sociedade. Esta é plural e complexa, o que não significa caos mas a presença de diversidade - diversidade de valores -, que o aparato de poder do Estado modeliza.

Enclausurados a família e seu reconhecimento, importa admitir que o direito vivencia um "esgotamento próprio de uma casca destacada da linfa subjacente", o que equivale a afirmar que o formalismo legalista em que o direito se constrói se apresenta como dimensão 
formal fundada não sobre fatos, mas sobre "a lei como apropriadora e intérprete única dos fatos transformou o terreno jurídico em um recinto fechado". Mais do que almejar um direito colhido como ordenamento da sociedade, que em momentos é utópico, presencia-se um direito como instrumento de poder, fruto de uma estratégia "do arranjo sociopolítico operante em um certo clima histórico". O resgate que se faz é de um direito que pertence "naturalmente" à sociedade, pois, como dimensão ordenadora, é ele que se propõe como "salvação histórica da sociedade, a qual se exprime em civilização, em tantas diversas fases das civilizações históricas", que também são jurídicas pois se pode contar com a "força historicamente vencedora do direito" (GROSSI, 2004, p. 10-14).

Neste sentido, apresenta-se uma cultura jurídica pós-moderna e, consequentemente, um Direito de Família pós-moderno, que, pautado na afetividade, comportaria um direito plural pela multiplicidade de entidades familiares; um direito reflexivo aberto a novos valores que circundam a família, como a moralidade sexual, equiparação entre homens e mulheres, perda de influência religiosa e o reconhecimento da filiação socioafetiva; um direito prospectivo, que projete a ordem jurídica da família para o futuro, por exemplo, na equiparação das uniões homoafetivas e no reconhecimento das uniões simultâneas; um direito discursivo, em que a linguagem esteja atrelada a um espaço familiar que promova o desenvolvimento espiritual e físico do ser humano; um direito relativo, que recuse os dogmas absolutos e inquestionáveis, como o divórcio; um direito coletivo, em que todos e todas sejam responsáveis uns pelos outros no ambiente familiar (SOARES, 2008). Trata-se de um Direito de Família que decide seu projeto de constituição, o planejamento familiar, o encaminhamento de seus conflitos, a permissividade de intromissão estatal e a decisão do caso concreto que permitirá sua autonomia de desenvolvimento.

A doutrina brasileira tem aplicado o princípio da afetividade em situações do Direito de Família, a saber: a) a partir da teoria tridimensional que apresenta o mundo genético, afetivo e ontológico (WELTER, 2012); b) no desempenho dos papéis masculino e feminino (PEREIRA, 2003); c) no desenvolvimento da personalidade do membros da família (TEPEDINO, 2004).

A partir da reflexão sobre o Direito de Família constitucionalizado, apresentam-se os fundamentos da teoria do pluralismo jurídico comunitário-participativo a fim de traduzir o perfil da família na Pós-Modernidade: sujeito coletivo de direito no sentido extrapatrimonial; legalidade e complexidade; conflituosidade e decidibilidade. Trata-se de um tripé que retrata a 
situação dos relacionamentos vividos no mundo pós-moderno - podem ser econômicos, políticos, filosóficos, culturais, religiosos e científicos. Mas, para a pesquisa, têm importância os conflitos de ordem relacional, quer sejam conjugais/convivenciais, quer sejam parentais.

$\mathrm{O}$ aporte da teoria do pluralismo jurídico comunitário-participativo se espraia para algumas categorias devidamente selecionadas e que possuem o condão de robustecer as ferramentas jurídicas disponíveis para o jurista do século XXI, cabendo a este tão somente usá-las. São categorias presentes na realidade mundial e que reclamam uma interpretação extensiva, muito além dos contornos ditados pelo pensamento jurídico moderno, pois pertencem à dimensão do ser, com suas relações interiores e exteriores. Por isso, optou-se pelas seguintes: a) sujeito de direito que entoa um comportamento de sujeito coletivo, que possui uma função social ancorada na coletividade, pois refuta-se o individualismo, marca da Modernidade que pautou, por exemplo, a redação do Código Civil de 1916; b) vive-se numa teia complexa: apostou-se na resposta utilizando-se a lei, e esta não consegue acompanhar o avanço dos "novos direitos", causando uma desordem jurídica; c) como sinalizadores desse caos, apresentam-se os conflitos que, unidos às decisões, comportam a grande ferramenta de intervenção na vida dos cidadãos, a qual nem sempre é justa, pois está pautada numa "lei individualista", merecendo uma intervenção participativa nos conflitos que se traduz pela via da mediação familiar.

\subsection{Sujeito coletivo de direito: a família}

O sujeito coletivo que se apresenta nesta pesquisa não é outro senão aquele que vence as abstrações do indivíduo trazidas pela Modernidade, aquele sujeito que só se manifesta em sua individualidade e que é fruto de uma dominação que a Modernidade foi acumulando, para se mostrar como um sujeito que busca incessantemente alternativas nas realidade que se apresentam, acolhendo as mudanças ocorridas (SANTOS, 2003, p. 105); esse é o ambiente para a configuração da família como sujeito coletivo de direito.

Salienta-se que a função social da família tem seu foco alterado quando esta deixa de ser um ente fechado, estanque, um fim em si mesmo e passa a ser um meio de "realização da dignidade e das potencialidades de seus membros", de forma coletiva, significando a realização moral e material daqueles que a compõem (GAMA, 2007, p. 119).

Desta forma, pode-se mencionar a família como sujeito coletivo de direito ou, como sugere Wolkmer (1997), um novo sujeito coletivo de juridicidade àqueles que se sentem 
imbuídos de constituir uma família, a todas as pessoas que nutrem esse desejo. Vai-se além da estipulação normativa que expressa a união entre homem e mulher: trazem-se outras fontes do Direito - no caso, a jurisprudência e resoluções - que permitam incluir nessa permissividade a união de todas as pessoas capazes, independentemente do gênero.

Desta forma, expõe-se: um "individual”, que em "pertencimentos coletivos" fica ainda adstrito às amarras da letra fria da lei e de um Estado controlador, requer uma virada de Copérnico ou um repensamento metodológico em que sujeito coletivo e sua função social historiem uma Pós-Modernidade jurídica pautada na inclusão, na democracia e num ordenamento jurídico que atenda questões complexas e seus conflitos e decisões.

\subsection{Legalidade e complexidade que envolvem as necessidades humanas fundamentais: a afetividade no ambiente familiar}

Se é verdade que tudo está em crise, a crise está posta em conceber a complexidade do real e, consequentemente, a complexidade do problema do conhecimento. Pode-se até pensar que não se saiu da pré-história do espírito humano e que, ao subdesenvolvimento do espírito, corresponde o subdesenvolvimento dos indivíduos, das relações intersubjetivas, das sociedades e da humanidade. Um grande paradoxo: acreditava-se ter chegado a um estágio supremo do pensamento e da consciência com um século marcado por Stalin, Hitler e Hiroshima, e chegou-se a um infantilismo do pensamento; não se conseguiu passar da complexidade inconsciente do cérebro à complexidade consciente do espírito - por isso a "possibilidade de futuro baseia-se no que representa o nosso presente: o atraso do nosso espírito em relação às suas possibilidades" (MORIN, 2008, p. 261).

Numa perspectiva de se observar a complexidade familiar, os sujeitos, a relação, a conjugalidade, a parentalidade e seus respectivos conflitos, tem-se que "aquilo que cabe ao pensamento complexo enxergar é justamente o que teima em não se apresentar; o que permanece oculto, embora ativo na produção da realidade" (CUNHA, 2006, p. 231).

O desafio da complexidade pós-moderna não é outro senão readequar a forma jurídica preservando liberdade, propriedade, Estado, segurança jurídica, democracia, Constituição, cuja dignidade do Direito será corroborada como instrumento efetivo e eficaz de mediação do novo a partir do conflito, com o Direito recuperando "a capacidade de atuar em tempo real e preventivamente; na urgência mesma do conflito, no momento crucial do justo" (PILATI, 2015, p. 15). 
A complexidade se estabelece nos pressupostos de novos sujeitos, a saber a família recomposta, aquela que se desvinculou duma primeira união e vem a se unir novamente, levando consigo todos os seus legados. Essa família recomposta pode ter origem no divórcio, na morte ou anulação/nulidade do casamento; essa segunda união pode se perfectibilizar pelo casamento ou união estável, fazendo com que surja a figura da madrasta/padrasto e os enteados/enteadas, além dos parentes por afinidade, como sogro/sogra e cunhado/cunhada, todos fazendo parte de um novo núcleo, que tem repercussão jurídica inclusive para postular o reconhecimento de filiação, dependendo do vínculo socioafetivo estabelecido entre padrasto/madrasta e enteados/enteadas.

Neste sentido, o julgamento do Recurso Extraordinário n. 898060, pelo Tribunal Pleno do Supremo Tribunal Federal, traduzido na tese de Repercussão Geral n. 622, traduz a afetividade na filiação nos moldes de que "A paternidade socioafetiva, declarada ou não em registro público, não impede o reconhecimento do vínculo de filiação concomitante baseado na origem biológica, com os efeitos jurídicos próprios."

Assim, a "afetividade é o indicador das melhores soluções para os conflitos familiares" (LÔBO, 2015, p. 121). Diante dessa constatação, afirma-se que a afetividade tem seu valor jurídico reconhecido no âmbito familiar.

\subsection{Prática interventivo-participativa nos conflitos: mediação familiar}

Cumpre delimitar que o olhar da presente pesquisa, por estar circunscrita à mediação familiar, é para os conflitos relacionais, ou seja, os concernentes às relações de conjugalidade/convivencialidade e parentalidade, o que refuta a análise dos conflitos intrapsíquicos, por exemplo, que são objeto de trabalho de outras áreas, como a Psicologia e a Psicanálise. Assim, o conflito tratado na mediação pode ser entendido como a divergência surgida na interação entre pessoas ou grupos sobre interesses, necessidades ou pontos de vista percebidos como incompatíveis. O conflito, em uma relação, é um processo que se constrói com a coparticipação e corresponsabilidade dos envolvidos, o que remete ao fato de que, na construção do conflito, todos os envolvidos contribuem, seja nas dimensões das ações, das emoções e das percepções.

O conflito é um fato da vida, pode ser positivo (quando presente para atingir objetivos) ou negativo (infligindo dano físico ou psicológico a um oponente). Assim, "para que haja conflito, é preciso, em primeiro lugar, que as forças confrontantes sejam dinâmicas, contendo 
em si o sentido da ação, reagindo umas sobre as outras" (SPENGLER, 2010, p. 242) ou, ainda, que haja divergência percebida de interesses e crenças fazendo que as aspirações conscientes das partes não possam ser alcançadas simultaneamente (ALOISIO, 1997, p. 25, tradução livre) $)^{4}$.

Nesse sentido, importa ressaltar que o conflito jurídico institucionalizado termina, tem um fim; já o conflito relacional, se institucionalizado, cai no beco de como se constrói sua decidibilidade - aqui destaca-se o marco regulatório da mediação, Lei n. 13.140, de 26 de junho de 2015.

A partir da teoria do pluralismo jurídico comunitário-participativo de Wolkmer (1997), apresenta-se a mediação familiar como uma prática participativa na intervenção necessária nos conflitos de ordem conjugal/convivencial e parental. É "preciso reconhecer que a mediação é uma ferramenta oriunda dos novos paradigmas da pós-modernidade, portanto, se trata de um conhecimento revestido de rigor científico" (BARBOSA, 2015, p. 189).

Percebe-se que a Lei de Mediação, Lei n. 13.140, não contempla entre seus princípios a interdisciplinaridade, o que vai de encontro ao contexto histórico, pois "a história da mediação no Brasil tem fundamento na interdisciplinaridade, portanto, seu papel não se limita à realização de acordos, mas atua para reduzir a litigiosidade no tecido social" (BARBOSA, 2015, p. 189). Para Morin (2000, p. 105), a disciplina

É uma categoria organizada dentro do conhecimento científico; ela institui a divisão e a especialização do trabalho e responde à diversidade das áreas que as ciências abrangem [...] tende naturalmente à autonomia pela delimitação das fronteiras, da linguagem em que ela se constitui, das técnicas que é levada a elaborar e utilizar e, eventualmente, pelas teorias que lhe são próprias.

A interdisciplinaridade deve ser estimulada no âmbito da mediação, implicando uma mudança na formação jurídica, de modo a dialogar-se com outras ciências ou esferas do conhecimento para se permitir vários olhares e saberes sobre o mesmo objeto. Essa necessidade e, consequentemente, sua relevância para se permitir uma mudança foram retratadas por Cappelletti e Garth (1988, p. 8, grifo dos autores):

Nenhum aspecto de nossos sistemas jurídicos modernos é imune à crítica. Cada vez mais pergunta-se como, a que preço e em benefício de quem estes sistemas de fato funcionam. Essa indagação fundamental que já produz inquietação em muitos advogados, juízes e juristas torna-se tanto mais perturbadora, em razão da invasão sem precedentes dos tradicionais domínios do Direito, por sociólogos, antropólogos, economistas, cientistas políticos e psicólogos, entre outros. Não devemos, no entanto, resistir a nossos invasores; ao contrário, devemos respeitar seus enfoques e reagir a eles de forma criativa. Através da revelação do atual modo de funcionamento de nossos sistemas jurídicos, os críticos

\footnotetext{
4 "Divergencia percibida de intereses o creencias que hace que las aspiraciones conscientes de las partes nos puedan ser alcanzadas simultáneamente.” (ALOISIO, 1997, p. 25).
} 
oriundos das outras ciências sociais podem, na realidade, ser nossos aliados na atual fase de uma longa batalha histórica - a luta pelo "acesso à justiça".

A mediação é um método fundamentado teórica e tecnicamente, "por meio do qual uma terceira pessoa, neutra e especialmente treinada, ensina os mediandos a despertarem seus recursos pessoais para que consigam, por eles próprios, com evidente mudança de comportamento, transformar o conflito" (BARBOSA, 2015, p. 37). Neste sentido, não se pode deixar de contextualizar a função do mediador, pois ele representa uma função entre os mediados, “[...] a função de levá-los a se conhecerem, a si e ao outro, análogo a um terceiro incluído para lhes refletir como são. Servir de função, para poderem reconhecer que o conflito final é somente ponta do ‘iceberg' e precisam ir mais fundo.” (MENDONÇA, 2008, p. 111).

A mediação seria uma fórmula admitida dentro das "regras do jogo"; por isso, para Wolkmer (1997, p. 81, grifos do autor),

\footnotetext{
Há que se compreender que a reinvenção permanente de "novos" direitos, que assumem dimensão individual, política e social, está diretamente relacionada com o grau de eficácia de uma resposta à situação ou condição de privação, negação ou ausência de "necessidades" fundamentais, "necessidades" configuradas como bens que servem para a satisfação e realização da vida humana.
}

O Direito, ao expor suas fronteiras, elege, não sem resistências, a interdisciplinaridade como um diálogo com o social: prima por um sistema aberto e plural, em contraposição à visão positivista-dogmática clássica que o constrói como um sistema fechado, posto que forças sociais, culturais, econômicas e científicas produzem relações intersubjetivas plurais e heterogêneas.

\section{CONCLUSÃO}

No século XXI, a família é transfronteiriça: apresenta-se com a possibilidade de ir além das limitações normativas que lhe são destinadas, de transpor as regras convencionais e prestar homenagem aos desejos e intenções de cada ser humano, para se traduzir em formatos que possuem como elo a afetividade. Por isso, reconhece-se que o Direito de Família, em especial, vivencia uma crise em seus conceitos e reconhecimentos, produzindo uma revolução pautada em novos elementos que permitam considerar a ocorrência de uma transição paradigmática apta a caracterizar uma dimensão pós-moderna.

Nesse sentido, curva-se para a constitucionalização do Direito de Família. Foi a $\mathrm{CRFB} / 88$ a ratio de uma nova ordem jurídica; ela separou o joio do trigo e reverenciou fundamentos, direitos, garantias e valores até então adormecidos no berço jurídico. A 
dignidade da pessoa humana como fundamento da República foi a sinalização de que a seiva que percorre a instituição familiar é a pessoa, o que ecoou na dignidade de seus membros. Ora, vivencia-se um caminho sem volta, em que vozes desafinadas até tentam entoar um canto com notas musicais preconceituosas e de exclusão, mas a orquestra está posta para apresentação e sua melodia é de inclusão, respeito e reconhecimento.

Inobstante a constituição da família, a tutela jurídica necessária para os conflitos familiares advém do paradigma do pluralismo jurídico comunitário-participativo, sobretudo a mediação, como forma de fortalecer o respeito ao espaço coletivo familiar. O sujeito coletivo de direito (a família), as necessidades humanas fundamentais (a afetividade) e a mediação como meio alternativo de intervenção nos conflitos familiares foram categorias eleitas pela pesquisa. A mediação se traduz como uma prática participativa, com método e metodologia próprios, além de regramento procedimental, que prima pela participação equânime dos envolvidos no conflito e, consequentemente, propicia sua emancipação para que possam (res)significar os conflitos atuais e vindouros. 


\section{REFERÊNCIAS}

ALOISIO, Victoria. Co-mediación: aporte emocional para fortalecer la relación con el otro. Buenos Aires: Ad-hoc S.R.L, 1997. 112 p.

BARBOSA, Águida Arruda. Mediação familiar interdisciplinar. São Paulo: Atlas, 2015.

CAPPELlETTI, Mauro; GARTH, Bryant. Acesso à justiça. Tradução de Ellen Gracie Northfleet. Porto Alegre: Fabris, 1988.

CUNHA, José Ricardo. Direito e complexidade. In: BARRETO, Vicente de Paulo (Coord.). Dicionário de filosofia do direito. São Leopoldo: Unisinos; Rio de Janeiro: Renovar, 2006.

FACHIN, Luiz Edson. Sobre o projeto do código civil brasileiro: crítica à racionalidade patrimonialista e conceitualista. Boletim da Faculdade de Direito da Universidade de Coimbra, Coimbra, v. LXXVI, 2000.

Direito de família: elementos críticos à luz do novo código civil brasileiro. 2. ed. Rio de Janeiro: Renovar, 2003.

. Família. In: BARRETO, Vicente de Paulo (Coord.). Dicionário de filosofia do direito. São Leopoldo: Unisinos; Rio de Janeiro: Renovar, 2006.

FERRAZ JÚNIOR, Tércio Sampaio. Introdução ao estudo do direito: técnica, decisão, dominação. 6. ed. São Paulo: Atlas, 2008.

GAMA, Guilherme Calmon Nogueira da (Coord.). Função social no direito civil. São Paulo: Atlas, 2007.

GROSSI, Paolo. A formação do jurista e a exigência de um hodierno "repensamento" epistemológico. Revista da Faculdade de Direito UFPR, Curitiba, v. 40, n. 0, 2004. Disponível em: <ojs.c3sl.ufpr.br/ojs2/index.php/direito/article/view/1731/1431>. Acesso em: 21 set. 2015.

. Para além do subjetivismo jurídico moderno. Tradução de Ricardo Marcelo Fonseca. In: Congresso Brasileiro de História do Direito, Curitiba, 2007. Digit.

LEHMANN, Leonardo Henrique Marques. O Ministério Público na pós-modernidade: a questão da participação popular nos assuntos de interesse coletivo. 2014. Digit.

LÔBO, Paulo Luiz Netto. Direito de família e os princípios constitucionais. In: PEREIRA, Rodrigo da Cunha (Org.). Tratado de direito das famílias. Belo Horizonte: IBDFAM, 2015.

MENDONÇA, Rafael. (Trans) modernidade e mediação de conflitos: pensando paradigmas, devires e seus laços com um método de resolução de conflitos. Florianópolis: Habitus, 2008.

MORIN, Edgar. Os sete saberes necessários à educação do futuro. 2. ed. Tradução de Catarina Eleonora F. da Silva, Jeanne Sawaya. São Paulo: Cortez, 2000. 
O método 3: conhecimento do conhecimento. Tradução de Juremir Machado da Silva. 4. ed. Porto Alegre: Sulina, 2008.

PEREIRA, Rodrigo da Cunha. Direito de família: uma abordagem psicanalítica. Belo Horizonte: Del Rey, 2003.

PILATI, José Isaac. A dimensão filosófica da pós-modernidade jurídica: ponto de partida de uma reconstrução paradigmática. Revista Seqüência, Florianópolis, n. 63, p. 291-317, dez. 2011.

Disponível

em:

<https://periodicos.ufsc.br/index.php/sequencia/article/view/21777055.2011v32n63p291/2106 7>. Acesso em: 10 jun. 2013.

. 3. ed. Rio de Janeiro: Lumen Juris, 2013.

Audiência pública na justiça do trabalho. Rio de Janeiro: Lumen Juris, 2015.

RUSSO, Eduardo Ángel. Teoria General del derecho: en la modernidad y en la pos modernidad. Buenos Aires: Abeledo-Perrot, 1996.

SANTOS, Boaventura de Souza. Pela mão de Alice: o social e o político na pósmodernidade. 9. ed. São Paulo: Cortez, 2003.

SPENGLER, Fabiana Marion. Da jurisdição à mediação: por uma outra cultura no tratamento de conflitos. Ijuí: Unijuí, 2010.

SOARES, Ricardo Mauricio Freire. O direito de família pós-moderno: breves apontamentos. Revista Brasileira de Direito das Famílias e Sucessões, Porto Alegre: Magister; Belo Horizonte: IBDFAM, v. 3 abr./maio 2008.

TEPEDINO, Gustavo (Coord.). Temas de direito civil. 3. ed. Rio de Janeiro: Renovar, 2004.

WELTER, Belmiro Pedro Marx. Teoria tridimensional do direito de família. Revista do Ministério Público do RS, Porto Alegre, n. 71, p. 127-48, jan./abr. 2012. Disponível em: <http://www.amprs.org.br/arquivos/revista_artigo/arquivo_1342124687.pdf>. Acesso em: 19 jan. 2015.

WOLKMER, Antônio Carlos. Pluralismo jurídico: fundamentos de uma nova cultura no direito. 2. ed. São Paulo: Alfa Omega, 1997.

. Pluralismo jurídico. In: BARRETO, Vicente de Paulo (Coord.). Dicionário de filosofia do direito. São Leopoldo: Unisinos; Rio de Janeiro: Renovar, 2006.

Pluralismo, justiça e legitimidade dos novos direitos. Revista Sequência, n. 54, p. 95 106, jul. 2007.

Introdução ao pensamento jurídico crítico. 8. ed. São Paulo: Saraiva, 2012.

Pluralismo crítico e perspectivas para um novo constitucionalismo na América 
Latina. In: WOLKMER, Antônio Carlos; MELO, Milena Petters. Constitucionalismo latinoamericano: tendências contemporâneas. Curitiba: Juruá, 2013. 